\title{
Erratum to: The Current Evidence Base and Future Needs in Improving Children's Well-Being Across Europe: is There a Case for a Comparative Longitudinal Survey?
}

\author{
Haridhan Goswami ${ }^{1}$ - Christopher Fox ${ }^{1}$. \\ Gary Pollock ${ }^{1}$
}

Published online: 18 March 2017

(C) Springer Science+Business Media Dordrecht 2017

\section{Erratum to: Child Ind Res (2016) 9:371-388 \\ DOI 10.1007/s12187-015-9323-5}

The article The Current Evidence Base and Future Needs in Improving Children's Well-Being Across Europe: is There a Case for a Comparative Longitudinal Survey?, written by [Haridhan Goswami, Christopher Fox and Gary Pollock], was originally published Online First without open access. After publication in volume [9], issue [2], page [371-388] the author decided to opt for Open Choice and to make the article an open access publication. Therefore, the copyright of the article has been changed to (C) The Author(s) [2016] and the article is forthwith distributed under the terms of the Creative Commons Attribution.

[continuing for CC BY license] 6.

4.0 International License (http://creativecommons.org/licenses/by/4.0/), which permits use, duplication, adaptation, distribution and reproduction in any medium or format, as long as you give appropriate credit to the original author(s) and the source, provide a link to the creative commons license, and indicate if changes were made.

The online version of the original article can be found at http://dx.doi.org/10.1007/s12187-015-9323-5

Haridhan Goswami

H.Goswami@mmu.ac.uk

1 Department of Sociology, Manchester Metropolitan University, Geoffrey Manton Building Rosamond Street West, Manchester M15 6LL, UK 